\title{
Contrasting the efficiency of radiation belt losses caused by ducted and nonducted whistler-mode waves from ground-based transmitters
}

\author{
Craig J. Rodger, ${ }^{1}$ Bonar R. Carson, ${ }^{1}$ Steven A. Cummer, ${ }^{2}$ Rory J. Gamble, ${ }^{1}$ \\ Mark A. Clilverd, ${ }^{3}$ Janet C. Green, ${ }^{4}$ Jean-André Sauvaud, ${ }^{5}$ Michel Parrot, ${ }^{6}$ \\ and Jean-Jacques Berthelier ${ }^{7}$ \\ Received 29 June 2010; revised 2 September 2010; accepted 6 October 2010; published 4 December 2010.
}

[1] It has long been recognized that whistler-mode waves can be trapped in plasmaspheric whistler ducts which guide the waves. For nonguided cases these waves are said to be "nonducted", which is dominant for $L<1.6$. Wave-particle interactions are affected by the wave being ducted or nonducted. In the field-aligned ducted case, first-order cyclotron resonance is dominant, whereas nonducted interactions open up a much wider range of energies through equatorial and off-equatorial resonance. There is conflicting information as to whether the most significant particle loss processes are driven by ducted or nonducted waves. In this study we use loss cone observations from the DEMETER and POES low-altitude satellites to focus on electron losses driven by powerful VLF communications transmitters. Both satellites confirm that there are well-defined enhancements in the flux of electrons in the drift loss cone due to ducted transmissions from the powerful transmitter with call sign NWC. Typically, $\sim 80 \%$ of DEMETER nighttime orbits to the east of NWC show electron flux enhancements in the drift loss cone, spanning a $L$ range consistent with first-order cyclotron theory, and inconsistent with nonducted resonances. In contrast, $\sim 1 \%$ or less of nonducted transmissions originate from NPM-generated electron flux enhancements. While the waves originating from these two transmitters have been predicted to lead to similar levels of pitch angle scattering, we find that the enhancements from NPM are at least 50 times smaller than those from NWC. This suggests that lower-latitude, nonducted VLF waves are much less effective in driving radiation belt pitch angle scattering.

Citation: Rodger, C. J., B. R. Carson, S. A. Cummer, R. J. Gamble, M. A. Clilverd, J. C. Green, J.-A. Sauvaud, M. Parrot, and J.-J. Berthelier (2010), Contrasting the efficiency of radiation belt losses caused by ducted and nonducted whistler-mode waves from ground-based transmitters, J. Geophys. Res., 115, A12208, doi:10.1029/2010JA015880.

\section{Introduction}

[2] Electromagnetic waves in the VLF range generated at or near Earth's surface can penetrate through the ionosphere and propagate within the plasmasphere. As these waves propagate in this part of geospace as circularly polarized whistler-mode waves, they may undergo wave-particle interactions with energetic electrons in the radiation belts

\footnotetext{
${ }^{1}$ Department of Physics, University of Otago, Dunedin, New Zealand. ${ }^{2}$ Electrical and Computer Engineering Department, Duke University, Durham, North Carolina, USA.

${ }^{3}$ British Antarctic Survey, NERC, Cambridge, UK.

${ }^{4}$ Space Weather Prediction Center, NOAA, Boulder, Colorado, USA.

${ }^{5}$ Centre d'Etude Spatiale des Rayonnements, Toulouse, France.

${ }^{6}$ Laboratoire de Physique et Chimie de l'Environnement et de l'Espace, Orleans, France.

${ }^{7}$ Centre d'Études des Environnements Terrestre et Planétaires, Saint Maur des Fosses, France.

Copyright 2010 by the American Geophysical Union. 0148-0227/10/2010JA015880
}

[Tsurutani and Lakhina, 1997], leading to pitch angle scattering. As strong sources of VLF radiation, both lightning discharges and man-made VLF transmitters have been implicated as significant drivers of electron loss from the inner radiation belts [e.g., Abel and Thorne, 1998, 1999; Rodger et al., 2004] through precipitation into the atmosphere.

[3] It has long been recognized that whistler-mode waves can be trapped in localized field-aligned enhancements in plasmaspheric ionization density termed "whistler ducts", which guide the waves from one hemisphere to the other [e.g., Al'pert, 1980; Al'pert, 1983]. Ducted propagation is required to explain the observation of lightning-generated whistlers by ground-based receivers at the location conjugate to the source; otherwise, the nonducted wave-normal angles do not allow transmission down through the conjugate ionosphere and reflection occurs. The occurrence and properties of whistler ducts are routinely monitored through cross-correlation experiments, observing whistler-mode signals produced by VLF communications transmitters which reach the conjugate hemisphere [Thomson, 1975; 
Clilverd et al., 2000]. Observations of whistler ducts indicate that ducting has an inner limit at L 1.6 [Thomson, 1987; Clilverd and Horne, 1996], as the field-aligned ducts are not sufficiently strong to guide the waves between the hemispheres at $L$ shells lower than this. Thus whistlermode waves generated near the Earth will propagate through the plasmasphere as nonducted waves for $L<1.6$, and as ducted or nonducted waves for higher $L$ shells, depending on the availability of whistler ducts. The nature of waveparticle interactions are influenced by the wave-normal angles, which are affected by the wave being ducted or nonducted. In the field-aligned ducted case, the dominant resonance is first-order cyclotron, whereas nonducted interactions open up a much wider range of energies through equatorial and off-equatorial gyroresonance [e.g., Lauben et al., 1999; Inan et al., 2007]. Thus the significance of VLF waves as drivers of radiation belt losses is strongly influenced by whether these waves are dominantly ducted or nonducted.

[4] At this point there is ambiguity in the literature as to whether the most significant loss processes are driven by ducted or nonducted waves. Significant work has been presented, describing the precipitation of radiation belt electrons due to wave-particle interactions with nonducted waves, produced by both lightning [e.g., Peter and Inan, 2004] and man-made VLF transmitters [Kulkarni et al., 2008]. The existence of nonducted waves in the plasmasphere has also been confirmed. Observations of transmissions from a VLF communications transmitter in Hawaii detected above the ionosphere in the conjugate hemisphere appear to confirm that this very low $L$ transmitter is a source of nonducted waves in the plasmasphere [Clilverd et al., 2008].

[5] However, there is some uncertainty as to the relative dominance of nonducted VLF waves as a driver of radiation belt losses. A recent study examined the decay rate of relativistic electrons $(2-6 \mathrm{MeV})$ in the slot region $(L=2)$, and concluded that the dominant loss process was a combination of plasmaspheric hiss and ducted lightning generated whistlers [Meredith et al., 2009]; in this study nonducted whistlers were found to have a negligible contribution to the decay rate. An experimental study using low-altitude DEMETER observations plus CRRES measurements from near the geomagnetic equator concluded that the dominant mode for wave power in the plasmasphere due to groundbased transmitters was ducted, for transmitters located with $L$ shells $>1.6$ [Clilverd et al., 2008]. In the case of the U.S. Navy transmitter in western Australia with call sign NWC ( $L=1.44)$, these authors concluded that the dominant propagation mode was a combination of nonducted $(L=$ 1.4-1.6) and ducted ( $L>1.6)$, depending on geomagnetic latitude. This is also consistent with experimental observations of $L=1.7-1.9$ NWC-produced DEMETER-observed $>100 \mathrm{keV}$ electron loss cone enhancements, which were shown to be comparatively narrow in energy and agreed with predictions from first-order cyclotron resonance (i.e., ducted interactions) [Sauvaud et al., 2008; Gamble et al., 2008], but do not appear to be consistent with those from nonducted calculations [Kulkarni et al., 2008].

[6] In particular, there is some ambiguity in the literature concerning the effect on $>100 \mathrm{keV}$ radiation belt electrons of VLF waves radiated by the large $\sim 500 \mathrm{~kW}$ U.S. Navy transmitter in Hawaii (21.4 kHz, call sign NPM), when contrasted with the more powerful transmitter $\sim 1$ MW NWC. Gamble et al. [2008] reported that 95\% of DEMETER nighttime orbits over NWC contained enhanced $>100 \mathrm{keV}$ electron fluxes in the drift loss cone, but that only 1 orbit in 36 over NPM contained an enhancement (i.e., 2.8\%). Datlowe and Imhof [1990] identified NPM as a transmitter that did not cause any nighttime cyclotron resonance events in S81-1 observations of electrons above $50 \mathrm{keV}$. This is in contrast with the conclusion of Inan et al. [2007], who found that NPM frequently induced precipitation, detected through a subionospheric experiment conducted while the transmitter was pulsed on and off. Graf et al. [2009] searched DEMETER $>100 \mathrm{keV}$ electron drift loss cone observations for evidence of enhanced fluxes when NPM was pulsed, but failed to find strong evidence this was occurring, with only $2.6 \%$ of passes showing the necessary signature.

[7] Previously, three different approaches have been used to search for evidence of transmitter-induced enhancements in $>100 \mathrm{keV}$ electron losses from the inner radiation belt. These are examining individual satellite orbits for enhancements during periods of continuous transmitter operation [e.g., Sauvaud et al., 2008; Gamble et al., 2008], looking for transient enhancements in local electron losses seen by satellite correlated with brief pulsed transmitter operation [e.g., Graf et al., 2009], and finally undertaking subionospheric propagation measurements of precipitation from the drift loss cone into the South Atlantic Magnetic Anomaly (SAMA) correlated with pulsed transmitter operation [e.g., Inan et al., 2007]. Making use of pulsed transmissions provides a very strong link to transmitter operation, but requires careful consideration of the relative positioning of the satellite, transmitter, and energy-dependent drift times. While less strongly linked to the transmitter operation, focusing on drift loss cone observations during continuous broadcast periods generates a very large data set of orbits, improving statistical certainty. By studying continuous transmitter operation times, larger flux enhancements are expected when compared with few-second pulsed operation [Graf et al., 2009].

[8] Clearly, the powerful VLF transmitter NWC scatters inner radiation belt electrons into the drift loss cone (DLC). The NWC-produced enhancements appear consistent with scattering by ducted waves [Gamble et al., 2008]. Theoretical calculations have suggested that nonducted waves originating from different transmitters should all produce significant pitch angle scattering [Kulkarni et al., 2008]. While there is agreement that the majority of the wave energy from the low-latitude transmitter NPM propagates as unducted waves through the plasmasphere, there is ambiguity in the literature whether these waves lead to significant pitch angle scattering. Thus in this study, we examine individual DEMETER orbits for $>80 \mathrm{keV}$ electron loss enhancements during periods of continuous transmitter operation to better characterize enhancements produced by NWC. We then focus on $>80 \mathrm{keV}$ DEMETER observations made in the region of NPM to determine if it is possible to observe any NPM-produced drift loss cone enhancements. As an independent test, we go on to use typical (median) loss cone measurements from the POES spacecraft to describe the $>100 \mathrm{keV}$ electron losses caused by NWC. 
Finally, in order to test the effectiveness of nonducted propagation scattering of electrons into the loss cone, we use $>100 \mathrm{keV}$ POES observations to examine the level of typical loss cone enhancements caused by the nonducted transmission from NPM. To the best of our knowledge this study represents the first attempt to compare the losses driven by NWC and NPM using the same techniques and data sets.

\section{Instrumentation}

\subsection{DEMETER}

[9] DEMETER is the first of the Myriade series of microsatellites, and was placed in a circular Sun-synchronous polar orbit at an altitude of $710 \mathrm{~km}$ at the end of June 2004. Data are available at invariant latitudes $<65^{\circ}$, providing observations around two local times $(\sim 1030$ LT and 2230 LT). The IDP particle instrument carried onboard DEMETER looks perpendicularly to the orbital plane of the satellite, and thus detects fluxes of $\sim 90^{\circ}$ pitch angle electrons inside, or just outside, the drift loss cone. This instrument is unusual in that it has very high energy resolution; in normal "survey" mode the instrument measures electron fluxes with energies from $70 \mathrm{keV}$ to $2.34 \mathrm{MeV}$, using 128 energy channels every $4 \mathrm{~s}$ [Sauvaud et al., 2006]. Energy resolution depends on the operational mode of the satellite, being either $17.8 \mathrm{keV}$ in "survey" mode or $8.9 \mathrm{keV}$ in "burst" mode. All burst mode data we consider in our study were downsampled to survey mode resolution in this study for homogeneity. The same spacecraft also carries the ICE instrument, which provides continuous measurements of the power spectrum of one electric field component in the VLF band [Berthelier et al., 2006]. Here we make use of both survey and burst mode data of the electric field spectra recorded up to $20 \mathrm{kHz}$, with a frequency channel resolution of $19.25 \mathrm{~Hz}$.

\subsection{AARDDVARK}

[10] We also make use of narrow-band subionospheric VLF data received at Dunedin, New Zealand $\left(45.9^{\circ} \mathrm{S}\right.$, $\left.170.5^{\circ} \mathrm{E}\right)$, which is part of the Antarctic-Arctic Radiationbelt Dynamic Deposition VLF Atmospheric Research Konsortia (AARDDVARK) [Clilverd et al., 2009]. More information on AARDDVARK can be found at the Konsortia website, http://www.physics.otago.ac.nz/space/AARDDVARK homepage.htm. Dunedin includes both OmniPAL [Dowden et al., 1998] and AbsPAL receivers [Thomson et al., 2005], although in this case we restrict ourselves to OmniPAL data. Both receiver types log the amplitude and phase of the MSK modulated transmissions. While the AARDDVARK observations have subsecond time resolution, we will restrict ourselves to $1 \mathrm{~min}$ median values to describe the overall transmitter operations.

\subsection{POES Electron Telescope Instrument}

[11] A complementary but independent electron flux data set to DEMETER is available from the Space Environment Monitor (SEM-2) instrument package onboard the Polar Orbiting Environmental Satellites (POES) which are in Sunsynchronous orbits at $\sim 800-850 \mathrm{~km}$ altitudes. SEM-2 includes the Medium Energy Proton and Electron Detector (MEPED), in addition to the Total Energy Detector (TED). Together these instruments monitor electron fluxes from $50 \mathrm{eV}$ up to $2700 \mathrm{keV}$. For a detailed description of the
SEM-2 instruments, see Evans and Greer [2004]. In this study we make use of SEM-2 observations from the NOAA 15 satellite, which measures at 5 LT (southward-going orbits) and 17 LT (northward-going orbits). All POES data is available from http://poes.ngdc.noaa.gov/data/; while the full-resolution data has $2 \mathrm{~s}$ time resolution, we work with the $16 \mathrm{~s}$ resolution ASCII files. The SEM-2 detectors include integral electron telescopes with energies of $>30 \mathrm{keV}$, $>100 \mathrm{keV}$, and $>300 \mathrm{keV}$, pointed in two directions. The $0^{\circ}$ pointing detectors are mounted on the three-axis stabilized POES spacecraft so that the center of each detector field of view is outward along the local zenith, parallel to the Earthcenter-to-satellite radial vector. Another set of telescopes, termed the $90^{\circ}$ detectors are mounted approximately perpendicular to the $0^{\circ}$ detector, directed toward the wake of the satellite motion. The telescopes pointing in the $0^{\circ}$ and $90^{\circ}$ directions are $\pm 15^{\circ}$ wide.

[12] POES user information suggests that the $0^{\circ}$ telescopes monitor particles in the atmospheric loss cone that will enter the Earth's atmosphere below the satellite when the spacecraft is poleward of about $35^{\circ}$, while at high latitudes the $90^{\circ}$ telescopes monitor particles which are trapped in the Van Allen radiation belts. In an earlier study, Rodger et al. [2010, Figure 1] presented a world map showing the changing radiation belt population observed by the $0^{\circ}$ directed MEPED telescopes onboard POES. These authors also noted that care must be taken with the $>30 \mathrm{keV}$ electron observations from the MEPED telescope, due to contamination by comparatively low-energy protons. As much as $\sim 42 \%$ of the $0^{\circ}$ telescope observations were typically found to be contaminated, although the situation was less marked for the $90^{\circ}$ telescope $(3.5 \%)$. In the current study we follow the "conservative" approach suggested by Rodger et al. [2010] to avoid periods with proton contamination. In Appendix A we expand on the work of Rodger et al. [2010] to determine what radiation belt populations (trapped, drift loss cone, etc) are viewed by the $0^{\circ}$ and $90^{\circ}$ directed MEPED telescopes onboard POES.

\section{DEMETER Observations of NWC-Produced DLC Enhancements}

[13] The powerful U.S. Navy transmitter with call sign "NWC" (19.8 kHz, 1 MW radiated power, North West Cape, Australia, $L=1.45$ ) is extremely well positioned to have a potential influence upon $>100 \mathrm{keV}$ electrons in the inner radiation belt; recent studies have confirmed that transmissions from this station lead to significant increases in drift loss cone energetic electron fluxes measured by lowEarth-orbiting spacecraft [Sauvaud et al., 2008; Gamble et al., 2008]. The location of NWC is shown in Figure 1. When contrasted with periods when NWC is nonoperational, there are typically $\sim 430$ times more $100-260 \mathrm{keV}$ electrons present in the drift loss cone across $L=1.67-1.9$ due to NWC transmissions [Gamble et al., 2008].

[14] The study of Gamble et al. [2008] manually examined DEMETER nighttime orbits from 12 August to 26 September 2005 and concluded that $\sim 95 \%$ of nighttime orbits east of NWC contained $\sim 80-400 \mathrm{keV}$ electron flux enhancements, and that only nighttime enhancements were possible because of transionospheric propagation attenuation levels. As part of the current study we have expanded 


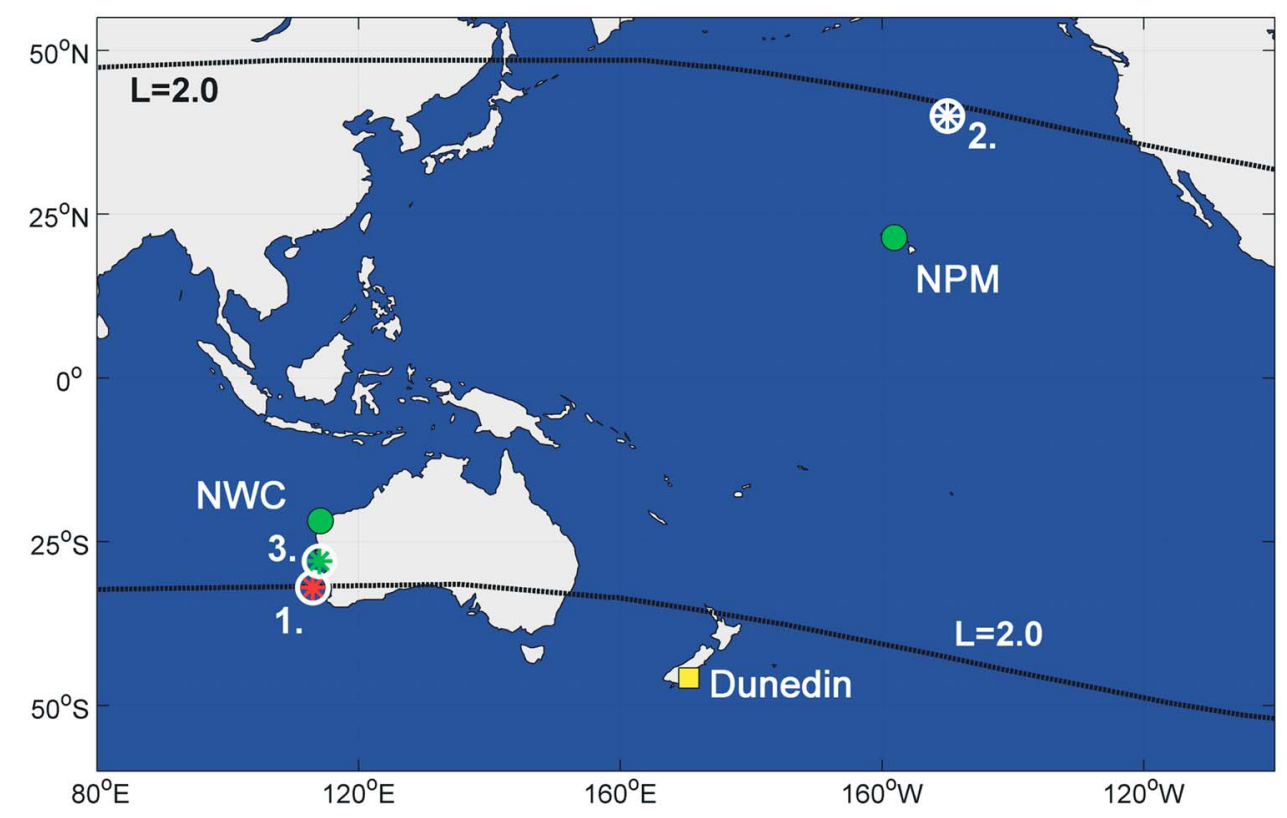

Figure 1. Schematic map of the situation considered in this study. The locations of the U.S. Navy VLF transmitters with call signs NWC and NPM (green circles) and the ground-based receiver in Dunedin (yellow square) are marked. The approximate location of the expected peak $>100 \mathrm{keV}$ electron precipitation caused by NWC (point 1 , red star, $L=2$ ) and NPM (point 2, white star, $L=1.9$ ) are taken from Kulkarni et al. [2008]. The approximate starting point of the POES-observed $>100 \mathrm{keV}$ loss feature is also given (point 3 , green star, $L=1.8$ ).

the Gamble et al. [2008] approach, by analyzing a much larger data set which included all the available orbits (within $\pm 25^{\circ}$ longitude of NWC in the southern hemisphere) from shortly after the launch of DEMETER, spanning 11 August 2004 through to 14 January 2009. Periods on which NWC was primarily nonoperational were not considered, identified through mean daily amplitude of NWC at the Dunedin AARDDVARK receiver. Consistent with the results of Gamble et al. [2008], DLC enhancements were common, particularly east of NWC's longitude. A total of 2128 DEMETER southern hemisphere orbits within $\pm 25^{\circ}$ longitude of NWC were manually examined on nights in which NWC was operational (1085 west and 1043 east), in which $989 \sim 80-400 \mathrm{keV}$ DLC electron flux enhancements were present (171 west and 818 east). The longitudinal distribution of the enhancements is shown in Figure 2, with the longitude of the transmitter marked by a thick dashed line. "Downstream" of the NWC transmitter $\sim 80 \%$ of these nighttime orbits contained electron flux enhancements, with typical occurrence rates that are essentially constant with longitude east of the transmitter.

[15] DEMETER produced maps of the VLF power from NWC in space have been produced previously [Gamble et al., 2008; Clilverd et al., 2008]. Figure 3 shows a DEMETER map of the VLF power due to NPM. Note that NPM broadcasts at $21.4 \mathrm{kHz}$, above the $20 \mathrm{kHz}$ Nyquist cutoff for DEMETER's ICE instrument. Thus, Figure 3 shows the aliased wave power at $18.6 \mathrm{kHz}$ and is not calibrated to physical units for the frequency of NPM. Consistent with earlier work [e.g., Clilverd et al., 2008], the NPM wave power is primarily located poleward of the conjugate point, consistent with primarily nonducted paths through the plasmasphere. In order to determine the significance of
NPM nonducted transmissions in producing transmitterinduced enhancements in $>80 \mathrm{keV}$ loss cone electron fluxes, we undertake the same analysis of DEMETER IDP orbits as for NWC. All 2487 DEMETER nighttime orbits occurring within $\pm 25^{\circ}$ longitude of NPM for times when NPM was operating (as identified from Dunedin AARDDVARK data) were manually examined for enhancements, including 1216 west of the transmitter and 1271 to the

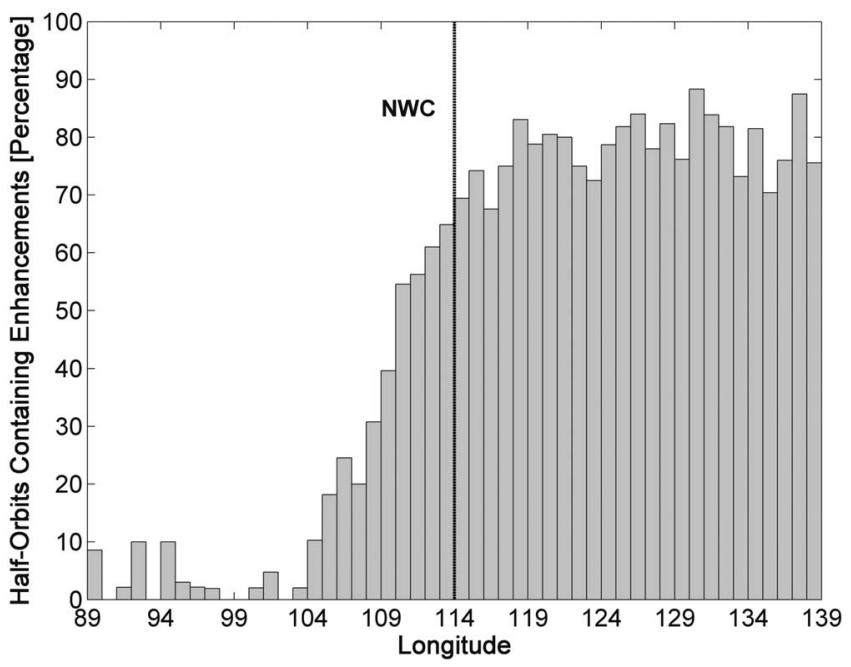

Figure 2. Variation with longitude of DEMETERobserved $\sim 80-400 \mathrm{keV}$ electron flux enhancements in Southern Hemisphere orbits within $\pm 25^{\circ}$ longitude of NWC. The longitude of the transmitter is shown by the thick dashed line. 


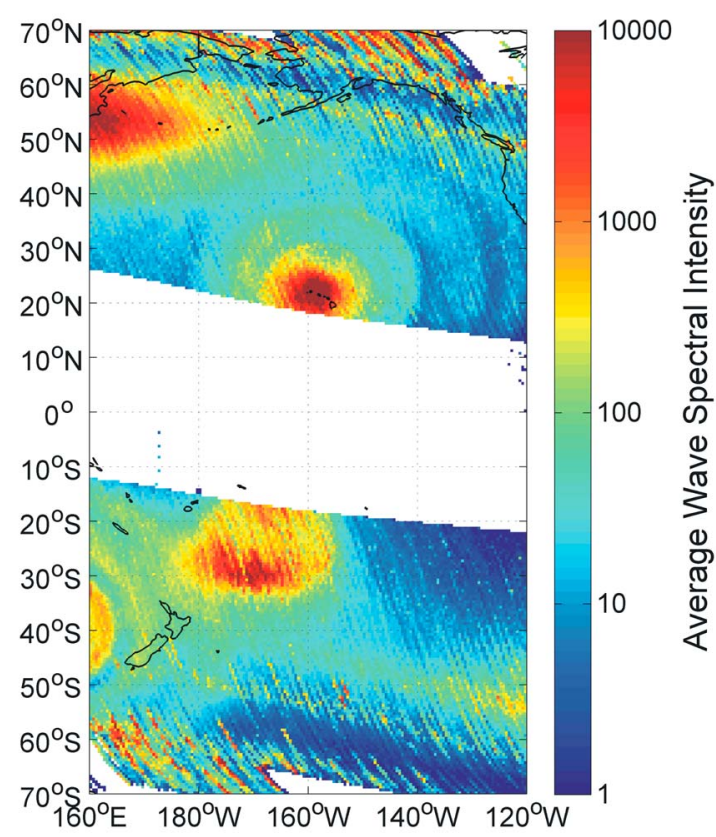

Figure 3. Average power received by the ICE instrument on DEMETER at $18.6 \mathrm{kHz}$ for night orbits spanning 1 January 2005 to 1 January 2009. Because of the $20 \mathrm{kHz}$ ICE sampling frequency, this map includes transmissions from NPM broadcasting at $21.4 \mathrm{kHz}$.

east, producing Figure 4. From Figure 4 it is clear that $>80 \mathrm{keV}$ DLC enhancements well west of NPM transmitter are fairly common, but are extremely uncommon directly above this transmitter, or "downstream" of NPM where one would expect the strongest occurrence rates (Figure 2 for NWC). The enhancements observed "upstream" of NPM (beyond $\sim 10^{\circ}$ west) are produced by electrons interacting with NWC, which have drifted eastward and are still present in the nighttime data near locations above NPM. The comparatively low occurrence rate is caused by seasonal changes in the timing of sunrise over NWC, which limits how far $\sim 80$ $300 \mathrm{keV}$ electrons can have drifted around the world to reach the DEMETER 22.5 LT observing point. Thus for part of the year the nighttime orbits slightly west of NPM can be affected by nighttime conditions over NWC. On the basis of Figure 4, NPM does not appear to have a significant effect on the radiation belts, with an average downstream occurrence rate of $1 \%$ (compared to $\sim 80 \%$ for NWC). The occurrence rate is no more than $5 \%$ for any given longitude bin and in total only 13 enhancement events for longitudes to the east of NPM are observed. To clarify further the low activity rate, of these 13 events only 5 are well defined "wisp like" enhancements (that is, similar to those presented in the previous literature), the rest are only "probable" events.

[16] Such a low occurrence rate is not consistent with pitch angle scattering from continuous NPM transmissions propagating in a nonducted mode, but rather very occasional coupling between the transmissions and $>80 \mathrm{keV}$ radiation belt electrons. One possibility would be occasional coupling of the transmissions from this very low $L$ transmitter into whistler ducts at $L>1.6$, as the rarely observed enhancements are all observed at $L>1.6$.
[17] Calculations presented by Graf et al. [2009] have established the expected signature of a DLC enhancement produced by nonducted transmissions from NPM. Graf et al. [2009, Figure 8c] indicate that at $L=1.9$ the loss cone electron flux would peak at $\sim 100 \mathrm{keV}$, falling off fairly smoothly with energy to be two orders of magnitude smaller at $250 \mathrm{keV}$. The experimentally observed DEMETER DLC enhancements do not span such a wide energy range at a given $L$, but are rather $40-50 \mathrm{keV}$ wide, centered on energy predicted by first-order cyclotron theory. Gamble et al. [2008, Figure 7] showed the variation with $L$ of the firstorder cyclotron resonance for NWC, which is essentially the same for NPM.

\section{Consideration of Pitch Angle Scattering by Ducted and Nonducted Transmissions Using POES Measurements}

[18] Given that DLC enhancements produced by NWC can be present near the longitudes of NPM, additional care must be taken when searching for the impact of NPM. Thus, as an independent test as to the effect on $>80 \mathrm{keV}$ radiation belt electrons from the ducted transmissions from NWC, and the nonducted transmissions from NPM, we examine loss cone measurements from the $>100 \mathrm{keV}$ MEPED $90^{\circ}$-directed telescope onboard POES N-15. Previous studies have identified NWC-produced DLC enhancements in POES $>100 \mathrm{keV}$ electron data [Gamble et al., 2008; Masuyama et al., 2009]. Figure 1 is a schematic map of the transmitters and the locations of interest we will focus upon during the current study. In particular, we will contrast the POES experimental observations of electron fluxes in the loss cone with those predicted in theoretical calculations due to pitch angle scattering from nonducted whistler-mode waves. Loss cone fluxes for electron energies $>100 \mathrm{keV}$ due to nonducted whistler-mode waves from NWC have been predicted to peak at $L=2$ and for NPM at $L=1.9$ [Kulkarni et al., 2008, Figure 7]. Based on a wholly nonducted approach, the

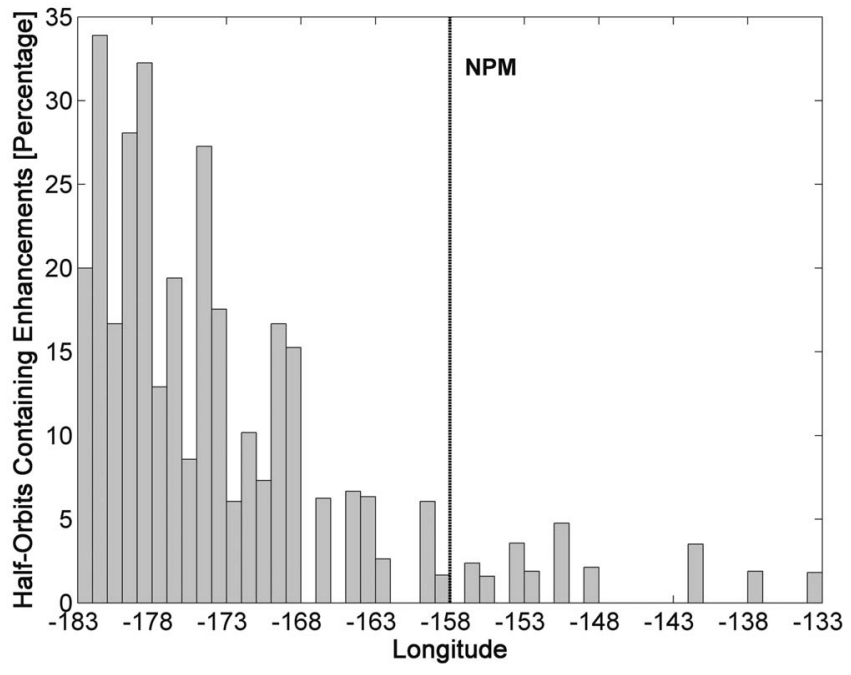

Figure 4. Variation with longitude of DEMETERobserved $\sim 80-400 \mathrm{keV}$ enhancements in Southern Hemisphere orbits within $\pm 25^{\circ}$ longitude of NPM. The longitude of the transmitter is shown by the thick dashed line. 
Table 1. Summary of the Equatorial Pitch Angle Observations for the Three Points of Interest in Figure $1^{\text {a }}$

\begin{tabular}{|c|c|c|c|c|c|c|c|c|c|}
\hline \multirow[b]{2}{*}{ Number $^{b}$} & \multirow[b]{2}{*}{ Location } & \multirow[b]{2}{*}{$\alpha_{\mathrm{BLC}}$} & \multirow[b]{2}{*}{$\alpha_{\text {DLC }}$} & \multicolumn{3}{|c|}{ Northward } & \multicolumn{3}{|c|}{ Southward } \\
\hline & & & & $\alpha$ & $\alpha_{+}$ & $\alpha_{-}$ & $\alpha$ & $\alpha_{+}$ & $\alpha_{-}$ \\
\hline 1 & $113^{\circ} \mathrm{E}, 32^{\circ} \mathrm{S}, L=2$ & $14.9^{\circ}$ & $20.5^{\circ}$ & $15.8^{\circ}$ & $17.1^{\circ}$ & $13.5^{\circ}$ & $15.7^{\circ}$ & $17.0^{\circ}$ & $13.3^{\circ}$ \\
\hline 2 & $210^{\circ} \mathrm{E}, 40^{\circ} \mathrm{N}, L=1.9$ & $19.5^{\circ}$ & 24.8 & $20.0^{\circ}$ & $22.0^{\circ}$ & $16.7^{\circ}$ & $19.1^{\circ}$ & $21.5^{\circ}$ & $15.3^{\circ}$ \\
\hline 3 & $114^{\circ} \mathrm{E}, 26^{\circ} \mathrm{S}, L=1.8$ & $18.9^{\circ}$ & $25.4^{\circ}$ & $19.5^{\circ}$ & $21.5^{\circ}$ & $16.2^{\circ}$ & $19.3^{\circ}$ & $21.4^{\circ}$ & $15.9^{\circ}$ \\
\hline
\end{tabular}

${ }^{\mathrm{a}}$ The table includes the field line bounce loss cone $\left(\alpha_{\mathrm{BLC}}\right)$ and drift loss cone angles $\left(\alpha_{\mathrm{DLC}}\right)$, the center pitch angle for the POES $90^{\circ}$ electron telescope $(\alpha)$, and the upper $\left(\alpha_{+}\right)$and lower $\left(\alpha_{-}\right)$limits observed by the telescope at each location.

${ }^{b}$ Number 1 is nonducted $>100 \mathrm{keV}$ peak NWC (red star in Figure 1), number 2 is nonducted $>100 \mathrm{keV}$ peak NPM (white star in Figure 1), and number 3 is DEMETER-observed $>100 \mathrm{keV}$ peak NWC (green star in Figure 1).

predicted loss cone $>100 \mathrm{keV}$ fluxes produced by NWC and NPM are essentially the same at $L=1.7$, NWC predicted fluxes are 3 times larger than NPM at $L=1.8$, and 7 times larger at $L=1.9$ (values scaled from Kulkarni et al. [2008, Figure 7f]). Sauvaud et al. [2008] found that the NWCproduced loss cone enhancement at $200 \mathrm{keV}$ was located at $L=1.7$, while Gamble et al. [2008] followed up with a complementary DEMETER study reporting that $100-260 \mathrm{keV}$ enhancements typically occurred in the $L$ shell range 1.67 1.9. We therefore select 3 locations for special consideration, as shown in Figure 1. These are (1) the approximate position for which $>100 \mathrm{keV}$ loss cone fluxes produced by resonance with NWC are expected to peak on the basis of nonducted transmissions ( $L=2$, red star in Figure 1), (2) the approximate position where NPM-produced fluxes are expected to peak on the basis of nonducted transmissions $(L=1.9$, white star in Figure 1) and (3) the approximate location for which $>100 \mathrm{keV}$ NWC-produced enhancements were observed in DEMETER data $(L=1.8$, green star in Figure 1). These locations and $L$ shells provide reference points to consider loss cone observations using the POES data. Table 1 summarizes the location of the three suggested points, and the equatorial pitch angle observations provided by the POES $90^{\circ}$ electron telescopes. Note that the locations are the subsatellite point of the POES spacecraft, and the $L$ shell refers to the satellite at this point. In all three cases the $90^{\circ}$ electron telescope is viewing the pitch angle range around the edge of the field line bounce loss cone (BLC), and hence will see a mix of local precipitation and electrons which will be lost once they have drifted around the world to the SAMA (i.e., BLC plus DLC). In addition, the telescope is viewing $\sim 40-50 \%$ of the pitch angles in the drift loss cone for all three points, and so has approximately equal sensitivity for electrons pitch angles scattered into the drift loss cone by man-made NWC or NPM transmissions.

[19] Initially, we consider the period 1 August to 11 December 2006. As shown in Figure 5, Dunedin AARDDVARK data indicates that both NWC and NPM were operating normally across this time window, broadcasting near continuously. Variation in the median amplitude received in Dunedin during the day is due to propagation in the Earth-ionosphere waveguide [Clilverd et al., 1999]. During the local Dunedin nighttime (LT $\approx \mathrm{UT}-12$ ), the received amplitude of NWC is high, while that of NPM is low. Note the features in the NPM amplitude at approximately 8 and 10 UT, these are caused by NPM pulsing as part of Stanford University-led studies into possible man-made precipitation caused by this transmitter [e.g., Inan et al., 2007; Graf et al., 2009]. Figure 6 presents the median $>100 \mathrm{keV}$ electron fluxes from POES for the selected time period calculated from daily median maps with $2^{\circ}$ resolution. Figure 6 (top) shows the median fluxes for southward-traveling orbits, i.e., $05 \mathrm{LT}$. This is just before sunrise in low latitude to midlatitude locations for most of the year, and hence a strong $>100 \mathrm{keV}$ loss cone enhancement is present due to NWC, starting from the green star (point 3, consistent with DEMETER), and stretching across the longitudes of NPM to $\sim 250^{\circ}$ longitude. Figure 6 (middle) shows the same energy flux observations for

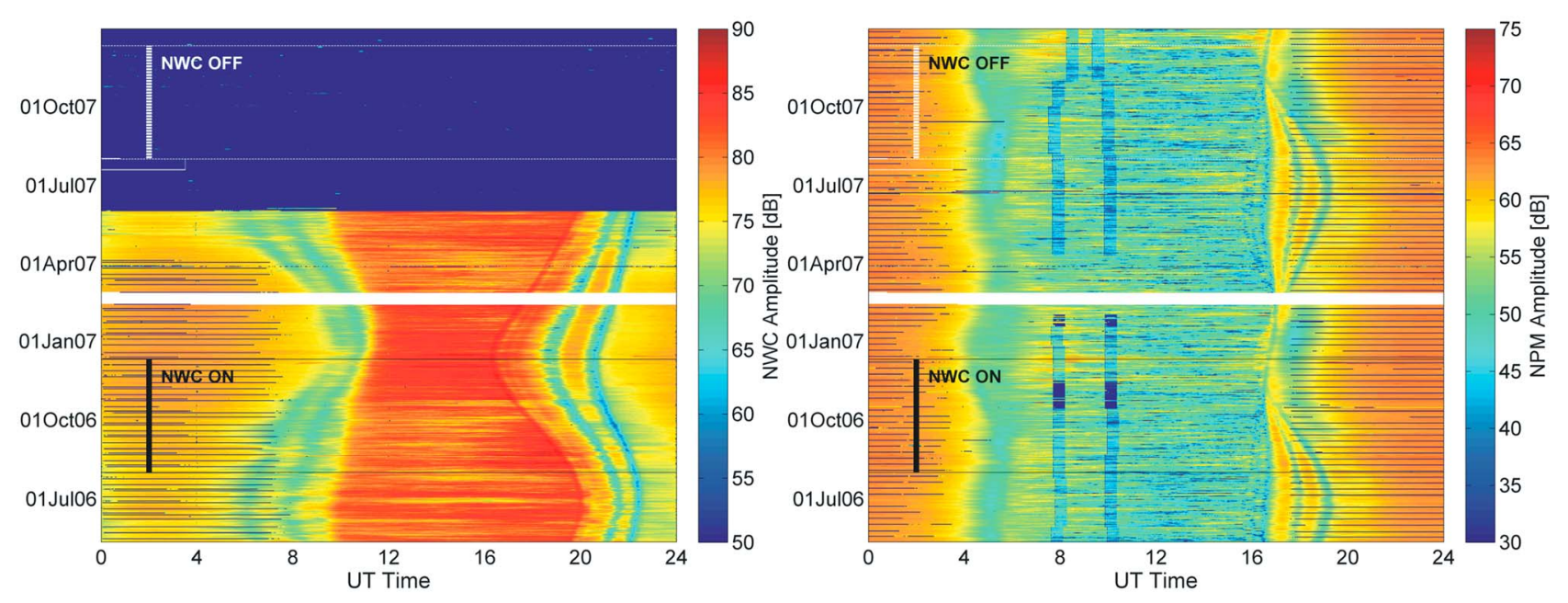

Figure 5. Median amplitudes from the transmitter (left) NWC and (right) NPM, received by the AARDDVARK instrument in Dunedin, New Zealand. The white sections correspond to missing data. Periods considered in Figures 6 and 7 are specifically marked (NWC on, Figure 6; NWC off, Figure 7). 

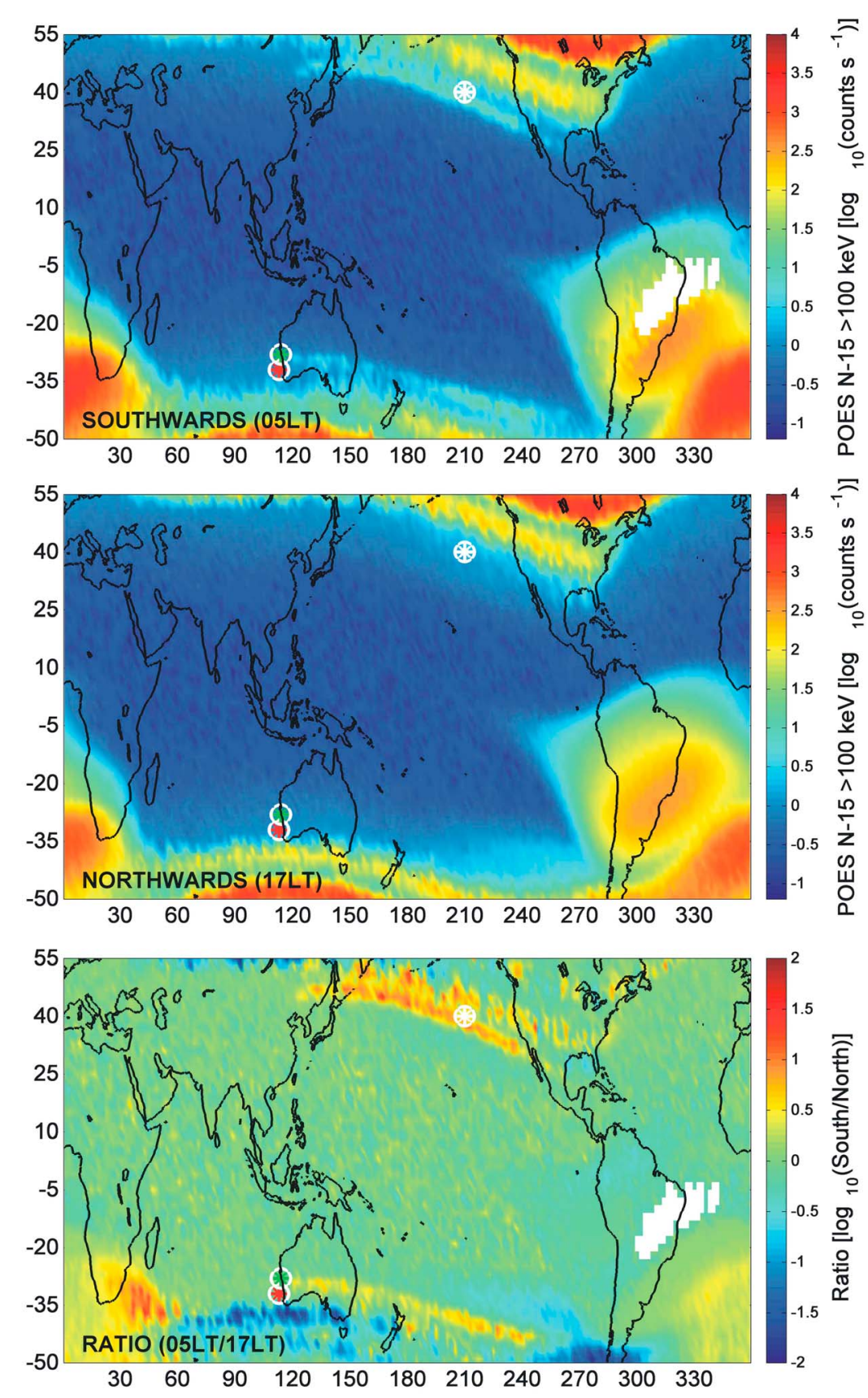

Figure 6. The effect of the NWC transmissions seen in the $>100 \mathrm{keV}$ electron observations from the POES N-15 spacecraft during 1 August to 11 December 2006 when NWC and NPM were operating normally. (top) The median electron counts from southward-going orbits (5 LT "night") and (middle) northward-going orbits (17 LT "day"). (bottom) The ratio between the Figures 6 (top) and 6 (middle).

northward-traveling orbits, i.e., 17 LT. As expected for daytime conditions, no transmitter-induced enhancements are observed. Figure 6 (bottom) shows the ratio of the southward to northward orbits, to emphasize the transmitterproduced feature. This appears as a factor of 3-30 increase in $>100 \mathrm{keV}$ POES loss cone fluxes, spanning $L=1.75$ 1.95. This location is wholly supportive with the location of NWC-produced enhancements reported by Gamble et al. [2008] in DEMETER data, which were consistent with first-order cyclotron resonance (i.e., ducted propagation). The observed upper $L$ shell limit is also consistent with resonance with $100 \mathrm{keV}$ electrons [Gamble et al., 2008, Figure 7]. The position of the POES observed $>100 \mathrm{keV}$ NWC-produced loss cone feature seen in Figure 6 (bottom), starting at the green star in agreement with DEMETER, is subtly different to that expected from nonducted calculations, with the peak fluxes seen equatorward of the predicted $L=2$ location marked by the red star, with no enhancement seen in the predicted nonducted peak location.

[20] Clearly, NWC produces a large enhancement in DLC $>100 \mathrm{keV}$ electron fluxes observed by POES N-15, which passes through the expected location of any (nonducted) 

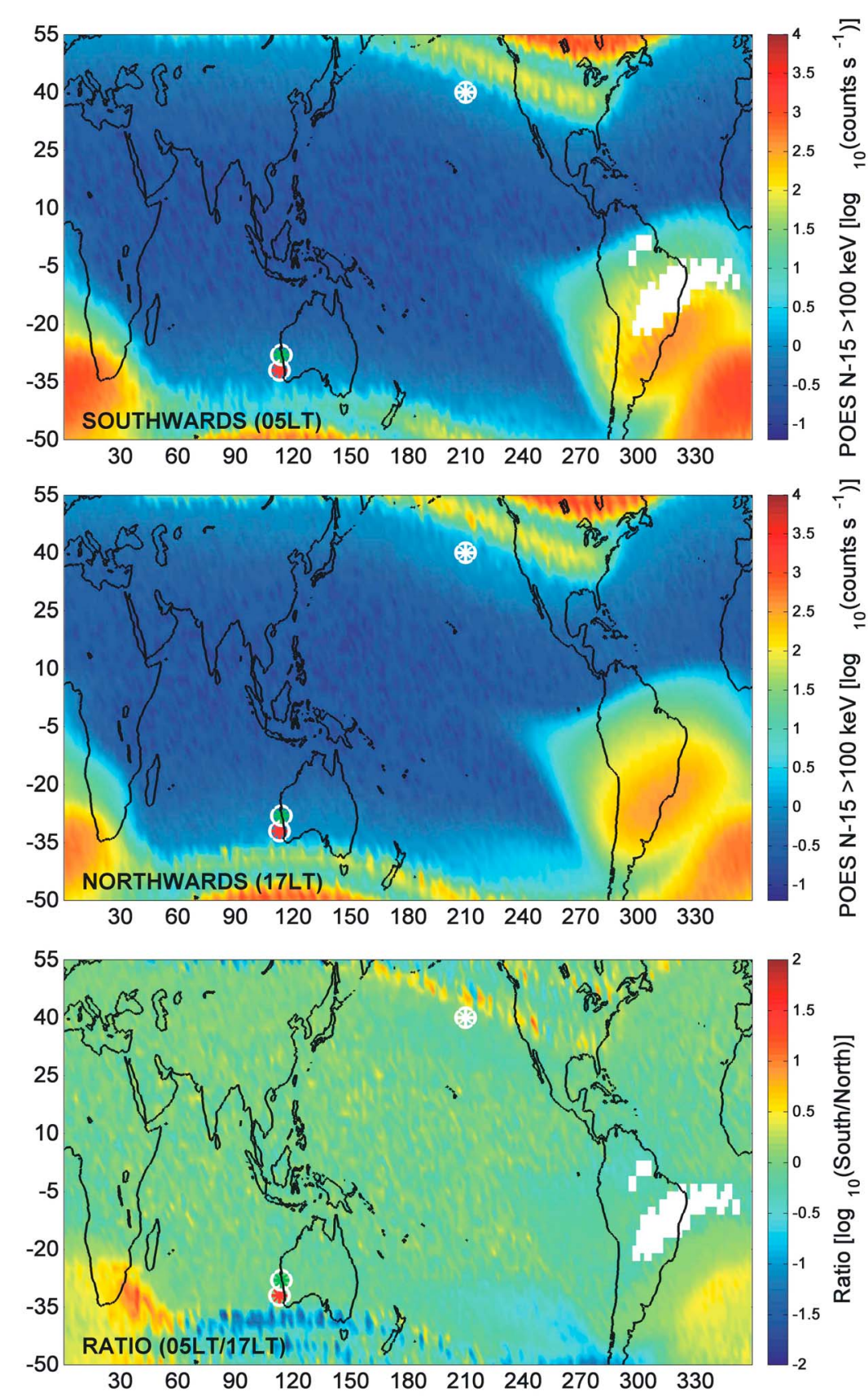

Figure 7. POES N-15 spacecraft $>100 \mathrm{keV}$ electron observations during 1 August to 11 December 2007 in the same format as Figure 6. NWC was not broadcasting in this period, while NPM was operating normally.

NPM-produced enhancement. This effectively masks any possible NPM contribution in the POES measurements. However, as seen in Figure 5, there was an unusually long time period in 2007 where NWC was not broadcasting, which we use to search for the nonducted effect of transmissions from NPM, free from the large enhancements produced by NWC. Thus, we repeat the analysis of Figure 6 for 1 August to 11 December 2007, presented in Figure 7. As expected, the POES DLC flux $>100 \mathrm{keV}$ enhancement attributed to NWC is missing in the electron loss cone observations. However, there is also no feature present which can be attributed to NPM. While the nonducted cal- culations suggest NPM should peak at $L=1.9$ (white star in Figure 7), with significant $>100 \mathrm{keV}$ loss cone fluxes present equatorward of this point, no scattering is observed. This has been checked using the northward-traveling orbits of the POES N-17 spacecraft, which takes measurements at 2150 LT (i.e., local night) for the same time period when NWC was not broadcasting. Once again, no transmitterproduced $>100 \mathrm{keV}$ feature is present (not shown). We estimate we could observe increases in the $\mathrm{N}-15$ night to day ratio as small as $\sim 20 \%$. As the NWC-produced $>100 \mathrm{keV}$ electron flux enhancement is $\sim 1000 \%$ (Figure 6 ), this suggests that any NPM enhancements are, at minimum, $\sim 50$ times 
smaller than those from NWC, and thus that calculations into the scattering of radiation belt electrons from nonducted whistler-mode waves overestimate the efficiency of this process.

\section{Discussion}

[21] One source of ambiguity as to the effectiveness of nonducted transmissions as a driver for inner radiation belt $>100 \mathrm{keV}$ electron losses comes from the apparently conflicting observations surrounding NPM. As noted earlier, during pulsed operation of this transmitter an analysis of subionospheric propagation measurements suggests that NPM frequently induced measurable precipitation [Inan et al., 2007]. However, this seems inconsistent with earlier satellite studies, which found NPM to have almost no effect [Datlowe and Imhof, 1990; Gamble et al., 2008; Graf et al., 2009]. In the case of the most recent studies, relying on DEMETER satellite observations, one suggested explanation is a mismatch in the range of pitch angles detected by DEMETER in the region of NPM [Graf et al., 2009]. However, DEMETER very clearly detects NWC-produced loss cone flux enhancements which are $>2$ orders of magnitude larger than the background level in the Hawaiian longitude range [e.g., Sauvaud et al., 2008, Figure 2], and hence would be expected to detect the similar magnitude enhancements [Kulkarni et al., 2008] in this $L$ shell range if they were caused by NPM. Such enhancements have been found to be very rare in our study, confirming the earlier satellite-based measurements.

[22] We also note that Graf et al. [2009] suggested that the pitch angle range detected by DEMETER might be poorly suited for the detection of NPM-produced loss enhancements. While the DEMETER observations around the longitude of NPM have a $\sim 10$ times higher background flux values than those around NWC due to the progressive filling of the DLC, a typical DEMETER-observed NWCproduced electron flux enhancement is $\sim 430$ times greater than the flux background present near NWC's longitudes [Gamble et al., 2008], and so should be $\sim 43$ times larger at NPM's longitudes. DEMETER observations over NPM during the local daytime commonly show clearly defined electron flux enhancements, which Gamble et al. [2008] attributed to electrons scattered into the DLC by NWC which then drift eastward across NPM. This interpretation is consistent with the average DEMETER-observed $>200 \mathrm{keV}$ electron flux map [Sauvaud et al., 2008, Figure 2], who show the NWC produced enhancement tracking smoothly from the local nighttime orbit observations (longitudes $0^{\circ}-$ $180^{\circ}$ ) through to the daytime orbit observations (longitudes $\left.-180^{\circ}-0^{\circ}\right)$. As such, any significant NPM-produced loss cone enhancements would be detectable in DEMETER data, if present.

\section{Summary and Conclusions}

[23] Numerous studies have confirmed that the powerful VLF transmitter NWC scatters inner radiation belt $>100 \mathrm{keV}$ electrons into the drift loss cone. Theoretical calculations have suggested that nonducted waves originating from different transmitters should all produce significant pitch angle scattering [Kulkarni et al., 2008], although the NWC- produced enhancements observed appear more consistent with pitch angle scattering by ducted waves through firstorder cyclotron resonance. While there is agreement that the majority of the wave energy from the low-latitude transmitter NPM propagates as unducted waves through the plasmasphere, there is ambiguity in the literature whether these lead to significant pitch angle scattering. Theoretical calculations based on nonducted propagation have predicted that the loss cone $>100 \mathrm{keV}$ fluxes caused by NPM should be between 1 and 7 times smaller than NWC, ranging across $\mathrm{L}=1.7-1.9$. However, there is ambiguity in the literature concerning experimental observations of the pitch angle scattering expected from NPM's nonducted transmissions. To clarify the effectiveness of the ducted waves originating from NWC, and the nonducted waves originating from NPM, at scattering radiation belt $>100 \mathrm{keV}$ electrons we have used independent satellite data sets from DEMETER and POES, combined with ground-based observations of NWC and NPM from the Dunedin AARDDVARK receiver. To the best of our knowledge this study represents the first attempt to compare the losses driven by the transmissions from NWC and NWC using the same techniques and data sets to consider both transmitters.

[24] Examining 2128 DEMETER nighttime orbits over 4.4 years which occurred within $\pm 25^{\circ}$ longitude of NWC, and when that transmitter was broadcasting, we identified 989 enhancements in $\sim 80-400 \mathrm{keV}$ drift loss cone radiation belt electron fluxes. "Downstream" of the NWC transmitter (i.e., to the east) $\sim 80 \%$ of these nighttime orbits contained enhancements, with typical occurrence rates that are essentially constant with longitude outside of the interaction region around the transmitter. DEMETER data was used in the same manner to test the impact of NPM, with 2487 DEMETER nighttime orbits examined around NPM when that transmitter was in operation. In contrast with NWC, only $\sim 1 \%$ of the orbits downstream of NPM showed a probable $>80 \mathrm{keV}$ DLC electron flux enhancements caused by this transmitter. Such a low occurrence rate is not consistent with pitch angle scattering from continuous NPM transmissions propagating in a nonducted mode, but rather very occasional coupling between the transmissions and radiation belt electrons. One possibility would be occasional coupling of the transmissions from this very low $L$ transmitter into whistler ducts at $L>1.6$, as the rarely observed enhancements are all observed at $L>1.6$.

[25] As there is some disagreement concerning the ability of DEMETER to observe drift loss cone enhancements expected from NPM, we have undertaken an independent test using SEM-2 observations from the POES. We have identified the radiation belt populations observed by the $0^{\circ}$ and $90^{\circ}$ directed MEPED telescopes onboard POES, and found that the $90^{\circ}$ directed MEPED telescope is viewing $\sim 40-50 \%$ of the pitch angles in the drift loss cone at the locations where the peak pitch angle scattering rates are expected. From the POES observations, we found an NWCproduced 3-30 increase in typical (median) $>100 \mathrm{keV}$ loss cone electron fluxes spanning $L=1.75-1.95$, an $L$ range of which is well represented by first-order cyclotron theory, and less consistent with the features predicted by nonducted resonances. This enhancement disappears when NWC is not broadcasting. 


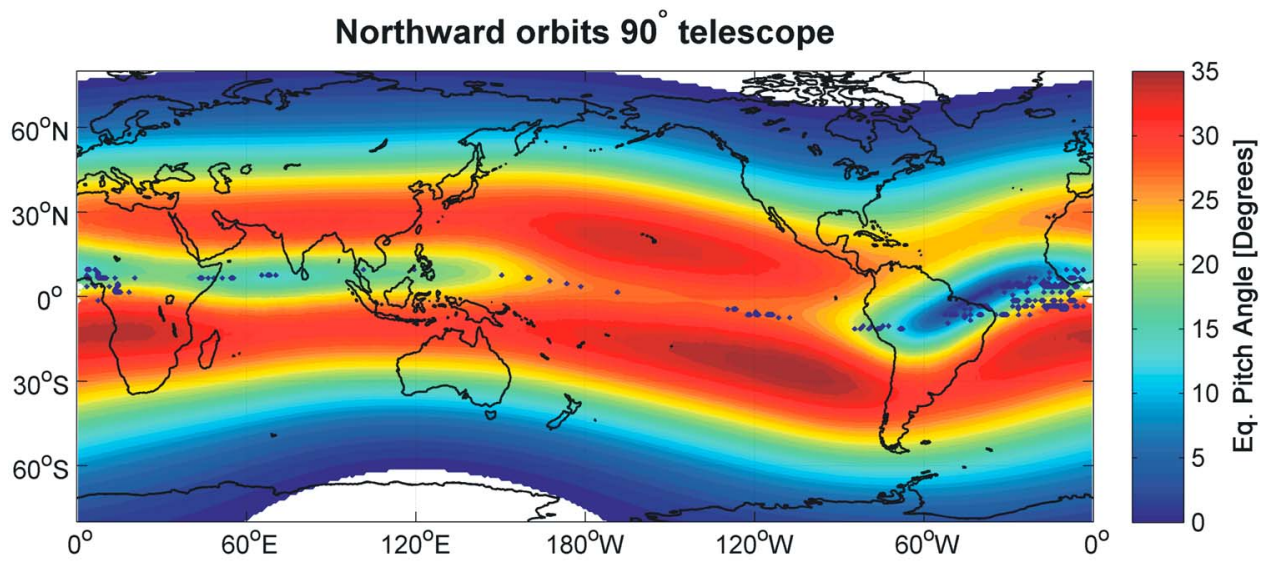

Southward orbits $90^{\circ}$ telescope

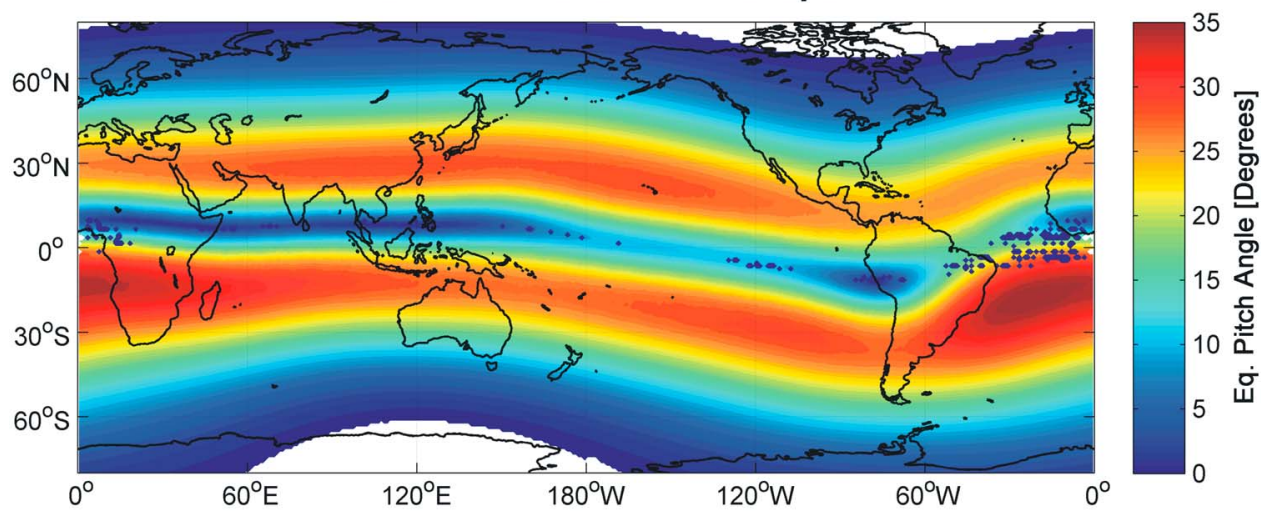

Figure A1. Typical (median) pitch angles for the center of the MEPED $90^{\circ}$ telescope, transformed to the geomagnetic equator and considered separately for northward- and southward-traveling orbits.

[26] In contrast, POES finds no detectable $>100 \mathrm{keV}$ DLC flux enhancement due to transmissions from NPM, indicating that such enhancements are, at minimum, $\sim 50$ times smaller than those from NWC suggesting that calculations into the scattering of radiation belt electrons from nonducted whistler-mode waves overestimate the efficiency of this process. This provides a partial test into the effectiveness of nonducted VLF waves in driving pitch angle scattering.

[27] However, we note that a true test would be best undertaken by contrasting the observed transmitter-produced electron flux enhancements with those predicted by wholly ducted or wholly nonducted modeling studies. In particular, the relationship between flux, energy, and $L$, and the energy width of the transmitter produced enhancement feature could be modeled through ducted and nonducted approaches. Based on the very broad energy features predicted by nonducted theory [e.g., Graf et al. 2009, Figure 8], in contrast with the apparent narrow features observed [Sauvaud et al., 2008, Figure 3; Gamble et al., 2008, Figure 3], this should provide a valuable test.

\section{Appendix A: Determining What the POES Telescopes Measure}

[28] We follow the approach outlined by Rodger et al. [2010] to examine radiation belt electron population observed by the MEPED $90^{\circ}$ telescope, but consider the northward and southward-going orbits separately, due to significant differences in the pitch angles viewed at high latitudes. The POES SEM-2 data files include the IGRFdetermined pitch angles of the particles detected by the $0^{\circ}$ and $90^{\circ}$ telescopes, at the spacecraft. Using the IGRF magnetic model for the altitude of the NOAA 15 spacecraft in mid-2005, we have determined the angular width of the bounce and drift loss cones at the satellite, and hence the geographical variation of the particle populations detected, taking into account that the MEPED telescopes are $\pm 15^{\circ}$ wide. Figure A1 presents the typical (median) pitch angles for the center of the $90^{\circ}$ telescope, transformed to the geomagnetic equator considered separately for northward and southward traveling orbits. Note that the deep blue dots near the geomagnetic equator are calculation artifacts, caused by IGRF-calculation failures when tracing near the equator.

[29] Figure A2 presents a world map of the changing radiation belt population observed by the $90^{\circ}$ directed, $\pm 15^{\circ}$ wide MEPED telescope. This plot is representative for all four POES spacecraft ( $\mathrm{N}-15$ through to $\mathrm{N}-18$, although we only consider observations from N-15 in this study). In Figure A2 " $\mathrm{T}$ " indicates trapped flux, "DLC" is drift loss cone, and "FL BLC" is field line bounce loss cone. Note that the FL BLC angle is defined as the largest of the two loss cone angles determined for the two hemispheres. In some 


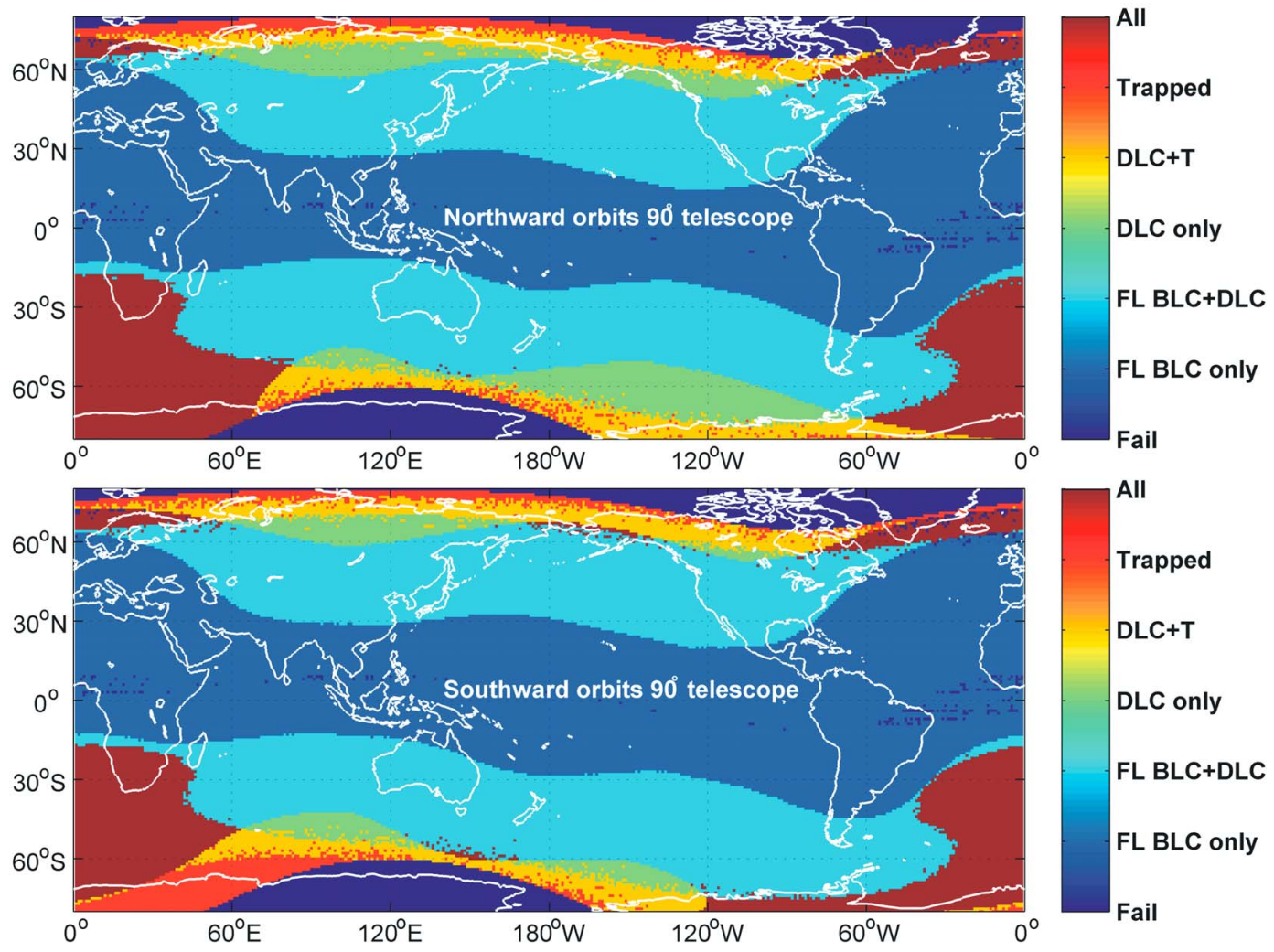

Figure A2. World map showing the changing radiation belt population observed by the $90^{\circ}$ directed, $\pm 15^{\circ}$ wide MEPED telescopes onboard POES. Here " $T$ " indicates trapped flux, "DLC" is drift loss cone, and "FL BLC" is field line bounce loss cone. For most locations where there is a significant radiation belt flux, it observes a mix of populations. 


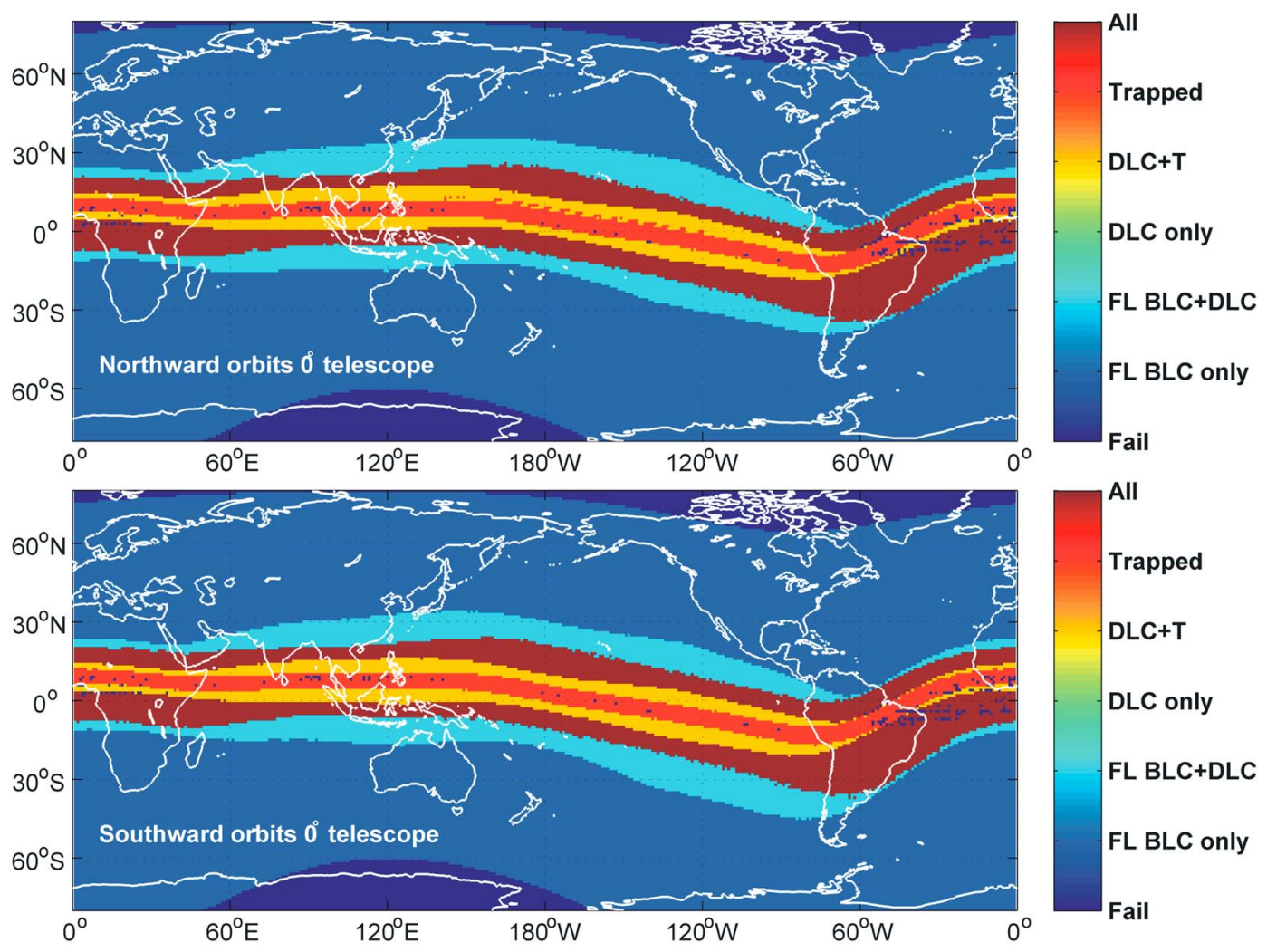

Figure A3. World map showing the changing radiation belt population observed by the $0^{\circ}$ directed, $\pm 15^{\circ}$ wide MEPED telescopes onboard POES, in the same format as Figure A2.

cases, where the magnetic field strengths at $100 \mathrm{~km}$ altitude are very different between the hemispheres, there can be a significant difference between the "local" BLC and the "conjugate" BLC; this is particularly strong in the longitudes around the Atlantic due to the SAMA. Near the geomagnetic equator the instrument only measures fluxes inside the bounce-loss cone (FL BLC), i.e., precipitating beneath the spacecraft, but over most of the globe it observes a mix of populations. Note that the red represents the regions in which the telescope observes only trapped fluxes (i.e., T), while the orange shade includes trapped and drift loss cone electrons (i.e., $\mathrm{T}+\mathrm{DLC}$ ). In practice, once even a small fraction of trapped electron fluxes are visible to the instrument these will strongly dominate over any fluxes inside a loss cone. This transition occurs at approximately $L=4.5-5$ in the northern hemisphere. Note that in the vicinity of the South Atlantic Magnetic Anomaly the instrument detects part of the BLC, all of the DLC, along with a fraction of the trapped population. Previous studies have previously identified well-defined NWC-produced enhancements in POES data from the $90^{\circ}$ directed MEPED telescope [Gamble et al., 2008; Masuyama et al., 2009], consistent with our modeling which indicates that this telescope is observing DLC+BLC electron fluxes in those $L$ shells and longitudes.

[30] Figure A3 shows the changing radiation belt population observed by the $0^{\circ}$ directed, $\pm 15^{\circ}$ wide MEPED telescopes onboard POES, in the same format as Figure A2. Although we do not use $0^{\circ}$ telescope data in the current study, the figure is included for completeness. Figure A3 is almost the same as the figure by Rodger et al. [2010] which combined both northward- and southward-going orbital directions, with only subtle differences.

[31] Acknowledgments. C.J.R. would like to thank Erin Darnton of Christchurch for her support. The work of J.A.S. and M.P. was supported by the Centre National d'Etudes Spatiales (CNES), while C.J.R. is a Guest Investigator inside the DEMETER program. S.A.C. was supported by a grant from the NSF Aeronomy program.

[32] Masaki Fujimoto thanks Hal Strangeways and another reviewer for their assistance in evaluating this manuscript.

\section{References}

Abel, B., and R. M. Thorne (1998), Electron scattering loss in earth's inner magnetosphere: 1. Dominant physical processes, J. Geophys. Res., 103 2385-2396, doi:10.1029/97JA02919.

Abel, B., and R. M. Thorne (1999), Correction to "Electron scattering loss in Earth's inner magnetosphere: 1. Dominant physical processes" and "Electron scattering loss in Earth's inner magnetosphere: 2. Sensitivity to model parameters" by Bob Abel and Richard M. Thorne, J. Geophys. Res., 104, 4627-4628, doi:10.1029/1998JA900121.

Al'pert, Y. L. (1980), 40 years of whistlers, J. Atmos. Terr. Phys., 42(1), 1-20, doi:10.1016/0021-9169(80)90117-8.

Al'pert, Y. L. (1983), The Near-Earth and Interplanetary Plasma, vol. 2, Plasma flow, Plasma Waves, and Oscillations, Cambridge Univ. Press, Cambridge, U. K.

Berthelier, J., M. Godefroy, F. Leblanc, M. Malingre, M. Menvielle, D. Lagoutte, J. Brochot, F. Colin, F. Elie, and C. Legendre (2006), ICE, the electric field experiment on DEMETER, Planet. Space Sci., 54, 456-471, doi:10.1016/j.pss.2005.10.016.

Clilverd, M. A., and R. B. Horne (1996), Ground-based evidence of latitude-dependent cyclotron absorption of whistler mode signals originating from VLF transmitters, J. Geophys. Res., 101, 2355-2367, doi:10.1029/95JA03153.

Clilverd, M. A., N. R. Thomson, and C. J. Rodger (1999), Sunrise effects on VLF signals propagated over long north-south paths, Radio Sci., 34 , 939-948, doi:10.1029/1999RS900052. 
Clilverd, M. A., B. Jenkins, and N. R. Thomson (2000), Plasmaspheric storm time erosion, J. Geophys. Res., 105, 12,997-13,008, doi:10.1029/ 1999JA900497.

Clilverd, M. A., C. J. Rodger, R. Gamble, N. P. Meredith, M. Parrot, J.-J. Berthelier, and N. R. Thomson (2008), Ground-based transmitter signals observed from space: Ducted or nonducted?, J. Geophys. Res. 113, A04211, doi:10.1029/2007JA012602.

Clilverd, M. A., et al. (2009), Remote sensing space weather events: Antarctic-Arctic Radiation-belt (Dynamic) Deposition-VLF Atmospheric Research Konsortium network, Space Weather, 7, S04001, doi:10.1029/ 2008SW000412.

Datlowe, D. W., and W. L. Imhof (1990), Cyclotron resonance precipitation of energetic electrons from the inner magnetosphere, J. Geophys. Res., 95, 6477-6491, doi:10.1029/JA095iA05p06477.

Dowden, R. L., S. F. Hardman, C. J. Rodger, and J. B. Brundell (1998), Logarithmic decay and Doppler shift of plasma associated with sprites, J. Atmos. Sol. Terr. Phys., 60, 741-753, doi:10.1016/S1364-6826(98) 00019-4

Evans, D. S., and M. S. Greer (2004), Polar Orbiting environmental satellite space environment monitor - 2: Instrument descriptions and archive data documentation, NOAA Tech. Memo. OAR SEC-93, version 1.4, Space Environ. Lab., Boulder, Colo.

Gamble, R. J., C. J. Rodger, M. A. Clilverd, J.-A. Sauvaud, N. R. Thomson, S. L. Stewart, R. J. McCormick, M. Parrot, and J.-J. Berthelier (2008), Radiation belt electron precipitation by man-made VLF transmissions, J. Geophys. Res., 113, A10211, doi:10.1029/2008JA013369.

Graf, K. L., U. S. Inan, D. Piddyachiy, P. Kulkarni, M. Parrot, and J. A. Sauvaud (2009), DEMETER observations of transmitter-induced precipitation of inner radiation belt electrons, J. Geophys. Res., 114, A07205, doi:10.1029/2008JA013949.

Inan, U. S., M. Golkowski, M. K. Casey, R. C. Moore, W. Peter, P. Kulkarni, P. Kossey, E. Kennedy, S. Meth, and P. Smit (2007), Subionospheric VLF observations of transmitter-induced precipitation of inner radiation belt electrons, Geophys. Res. Lett., 34, L02106, doi:10.1029/2006GL028494.

Kulkarni, P., U. S. Inan, T. F. Bell, and J. Bortnik (2008), Precipitation signatures of ground-based VLF transmitters, J. Geophys. Res., 113, A07214, doi:10.1029/2007JA012569.

Lauben, D. S., U. S. Inan, and T. F. Bell (1999), Poleward-displaced electron precipitation from lightning-generated oblique whistlers, Geophys Res. Lett., 26, 2633-2636, doi:10.1029/1999GL900374.

Masuyama, N., M. Hareyama, S. Kodaira, K. Sakurai, and N. Hasebe (2009), Narrow spikes enhanced by electron precipitation under the inner radiation belt, J. Phys. Soc. Jpn., 78, 146-148.

Meredith, N. P., R. B. Horne, S. A. Glauert, D. N. Baker, S. G. Kanekal, and J. M. Albert (2009), Relativistic electron loss timescales in the slot region, J. Geophys. Res., 114, A03222, doi:10.1029/2008JA013889.

Peter, W. B., and U. S. Inan (2004), On the occurrence and spatial extent of electron precipitation induced by oblique nonducted whistler waves, J. Geophys. Res., 109, A12215, doi:10.1029/2004JA010412.
Rodger, C. J., R. J. McCormick, and M. A. Clilverd (2004), Testing the importance of precipitation loss mechanisms in the inner radiation belt, Geophys. Res. Lett., 31, L10803, doi:10.1029/2004GL019501.

Rodger, C. J., M. A. Clilverd, J. Green, and M.-M. Lam (2010), Use of POES SEM-2 observations to examine radiation belt dynamics and energetic electron precipitation in to the atmosphere, J. Geophys. Res., 115, A04202, doi:10.1029/2008JA014023.

Sauvaud, J. A., T. Moreau, R. Maggiolo, J.-P. Treilhou, C. Jacquey, A. Cros, J. Coutelier, J. Rouzaud, E. Penou, and M. Gangloff (2006), High-energy electron detection onboard DEMETER: The IDP spectrometer, description and first results on the inner belt, Planet. Space Sci., 54, 502-511, doi:10.1016/j.pss.2005.10.019.

Sauvaud, J.-A., R. Maggiolo, C. Jacquey, M. Parrot, J.-J. Berthelier, R. J. Gamble, and C. J. Rodger (2008), Radiation belt electron precipitation due to VLF transmitters: Satellite observations, Geophys. Res. Lett., 35, L09101, doi:10.1029/2008GL033194.

Thomson, N. R. (1975), Whistler-mode signals: Group delay by crosscorrelation, Geophys. Res. Lett., 2, 451-452, doi:10.1029/GL002i010p00451.

Thomson, N. R. (1987), Experimental observations of very low latitude man-made whistler-mode signals, J. Atmos. Terr. Phys., 49, 309-319, doi:10.1016/0021-9169(87)90027-4.

Thomson, N. R., C. J. Rodger, and M. A. Clilverd (2005), Large solar flares and their ionospheric $D$ region enhancements, J. Geophys. Res., 110, A06306, doi:10.1029/2005JA011008.

Tsurutani, B. T., and G. S. Lakhina (1997), Some basic concepts of wave-particle interactions in collisionless plasmas, Rev. Geophys., 35 , 491-501, doi:10.1029/97RG02200.

Jean-Jacques Berthelier, Centre d'Etudes des Environnements Terrestre et Planétaires, 4 Ave. de Neptune, F-94100 Saint Maur des Fosses, France. (jean-jacques.berthelier@cetp.ipsl.fr)

B. R. Carson, R. J. Gamble, and C. J. Rodger, Department of Physics, University of Otago, P.O. Box 56, Dunedin 9016, New Zealand. (bonar@ physics.otago.ac.nz; rgamble@physics.otago.ac.nz; crodger@physics. otago.ac.nz)

M. A. Clilverd, British Antarctic Survey, NERC, High Cross, Madingley Road, Cambridge CB3 0ET, UK. (macl@bas.ac.uk)

S. A. Cummer, Electrical and Computer Engineering Department, Duke University, PO Box 90291, Durham, NC 27708, USA. (cummer@ee.duke. edu)

J. C. Green, Space Weather Prediction Center, NOAA, 325 Broadway Blvd., Boulder, CO 80305, USA. (janet.green@noaa.gov)

M. Parrot, Laboratoire de Physique et Chimie de l'Environnement et de 1'Espace, 3A Ave. de la Recherche Scientifique, F-45071 Orleans Cedex 2, France. (mparrot@cnrs-orleans.fr)

J. A. Sauvaud, Centre d'Etude Spatiale des Rayonnements, 9 Ave. du Colonel Roche, F-31028 Toulouse Cedex 4, France. (sauvaud@cesr.fr) 